\title{
EV71 virus-like particles produced by co-expression of capsid proteins in yeast cells elicit humoral protective response against EV71 lethal challenge
}

Xiaowen Wang ${ }^{1}$, Xiangqian Xiao' ${ }^{1}$ Miao Zhao ${ }^{1}$, Wei Liu' ${ }^{1}$, Lin Pang ${ }^{2}$, Xin Sun ${ }^{3}$, Shan Cen ${ }^{4}$, Burton B. Yang ${ }^{5}$, Yuming Huang ${ }^{2^{*}}$, Wang Sheng ${ }^{1 *}$ and Yi Zeng ${ }^{1}$

\begin{abstract}
Background: Enterovirus 71 (EV71) is the most common causative pathogens of hand, foot and mouth disease (HFMD) associated with severe neurological complications. There is a great need to develop prophylactic vaccine against EV71 infection.

Results: EV71 virus-like particle (VLP) was produced in yeast expression system by the co-expression of four EV71 structural proteins VP1-VP4. Immunization with the recombinant VLPs elicited potent anti-EV71 antibody responses in adult mice and anti-VLP sera were able to neutralize EV71 virus in vitro. Neonatal mice model demonstrated VLP immunization conferred protection to suckling mice against the lethal viral challenge.
\end{abstract}

Conclusions: Co-expression of four EV71 structural proteins VP1-VP4 in yeast expression systems is an effective method to produce EV71 VLPs. VLP-based vaccine shows great potential to prevent EV71 infection.

Keywords: Enterovirus 71, Vaccine, Yeast, Virus-like particle, Hand foot and mouth disease

\section{Background}

Human enterovirus 71 is a non-enveloped RNA virus of the Picornaviridae family that was first reported in 1969. The virion is around $25-30 \mathrm{~nm}$ in diameter containing a single-stranded RNA viral genome of approximately 7500 nucleotides [1-3]. EV71 encoded a single large polyprotein that is initially cleaved into P1, P2, and P3 regions. The $\mathrm{P} 1$ region is subsequently processed by protease $3 \mathrm{CD}$ to generate four capsid subunit proteins, VP1 to VP4. The viral genome is packaged in an icosahedral capsid which is composed of 60 copies of structural proteins. Highresolution structural analysis showed that VP1-3 form a

\footnotetext{
*Correspondence: hyming@medmail.com.cn; shengwang@bjut.edu.cn ${ }^{1}$ College of Life Science and Bioengineering, Beijing University of Technology, 100 Pingleyuan, Chaoyang District, Beijing, People's Republic of China

${ }^{2}$ Department of Neurology, Beijing Ditan Hospital, Capital Medical University, Beijing, People's Republic of China

Full list of author information is available at the end of the article
}

pseudo $\mathrm{T}=3$ icosahedral capsid that are located on the surface of viral capsid [4]. VP4 is myristoylated at the N terminus and located inside virion $[5,6]$. However, crystallographic analysis demonstrated that the structure of mature EV71 virion is similar to other enteroviruses [7].

EV71 has been identified as one of the major etiological agents of hand, foot and mouth disease (HFMD) [8, 9]. A number of HFMD epidemics caused by EV71 infection occurred in the Asia-Pacific region and are associated with severe neurological complications such as aseptic meningitis, poliomyelitis-like paralysis and brainstem encephalitis. The surveillance data from National Center for Disease Control and Prevention showed that more than 3 million HFMD cases and 1384 deaths were reported by the end of 2010 in mainland China [10-14]. HFMD is becoming the most common viral disease in these areas that seriously threat children health. However, no appropriate vaccine is yet available to prevent EV71 infection. 
Vaccination is the most optimal way to prevent and reduce prevalence of viral infectious diseases. Neutralizing antibody plays an essential role in the protection of suckling mice against EV71 infection, because immunization of maternal mice with inactivated EV71 can confer protection to neonatal mice against EV71 lethal challenge [15]. Several linear immunodominant epitopes were screened and successfully identified in EV71 structural proteins [16-20]. In recent years, recombinant virus-like particle (VLP)-based vaccine strategies have been frequently used for novel vaccine design. Vaccines based on viral VLPs have been successfully used in prevention against hepatitis $B$ virus and human papillomavirus [21-23]. VLPs are empty non-infectious viral capsids that structurally mimic the conformation of native virion. High density of viral linear and conformational epitopes on the VLP surface may elicit strong immune responses [23]. In the present study, EV71 VLPs were successfully produced by co-expression of four structural viral proteins in yeast, which is safe, reliable and cost-effective platform for recombinant protein production.

\section{Results}

\section{Generation and characterization of EV71 VLPs}

EV71 capsid is composed of 60 copies of each of the four viral structural proteins VP1, VP2, VP3 and VP4. In the present study, genes encoding VP1, VP2, VP3 and VP4 proteins of EV71 were inserted into vectors for co-expression of four viral proteins in yeast (Fig. 1). The expressions of viral proteins were investigated by SDS-PAGE and Western-blot. Viral proteins were purified using the method described previously with modification [3] and visualized using SDSPAGE analysis. Three bands were observed which corresponded to VP1, VP2 and VP3 of EV71 virus, respectively, according to the molecular weight of each band (Fig. 2a). However, the band corresponding to EV71 VP2 protein was further proofed by using VP2-specific antibody MAB979 by Western-blot (Fig. 2b). To determine whether the coexpression of four viral structural proteins can generate EV71 VLPs, total proteins of yeast cells were extracted and loaded onto the sucrose and cesium chloride gradient to isolate EV71 VLPs by ultracentrifugation. As shown in Fig. 2c, the formation of viral VLPs were observed in purified yeast lysates by transmission electron microscope and the diameters of particles were about 25-27 nm which appeared icosahedral. Our data indicate that co-expression of four viral structural proteins VP1, VP2, VP3 and VP4 in yeast cells can definitely lead to the formation of EV71 VLPs.

\section{VLP immunization elicits neutralizing antibody responses against EV71}

To investigate whether the EV71 VLPs were capable of inducing anti-EV71 antibody responses, female BALB/c mice were immunized i.m. with either purified VLPs, denatured VLPs or inactivated EV71 virus at the dose of $20 \mu \mathrm{g} /$ mouse and received booster injections 3 weeks later. Mice immunized with yeast cell lysates and PBS were used as negative controls. The immunized animals were bled at week $0,2,5,8$ for serological analysis. The results showed that anti-EV71 IgG antibodies became detectable in mice immunized by EV71 VLPs, denatured VLPs and inactivated-EV71 virus at 2 weeks after inoculation. The titers were enhanced by booster injection and reached a maximum titration at week 5 . No anti-EV71 antibody response was detected in the yeast cell lysatesimmunized group and the PBS group (Fig. 3). Our results demonstrated that EV71 VLPs, denatured VLPs and inactivated-EV71 virus induced similar levels of anti-EV71 antibody.

To evaluate whether the antibodies were able to neutralize EV71 virus, mouse serum samples were twofold serially diluted and mixed with infectious EV71 (100 $\mathrm{TCID}_{50}$ ) to test their ability to neutralize the live EV71 virus in vitro. EV71 Bj08 (genotype C4) and a variant of the prototype strain of EV71, BrCr-TR (genotype A) were used for in vitro neutralization assay. As shown in Fig. 4, remarkable increase in anti-EV71 neutralizing antibody titers was observed after the booster injection at 3 weeks post-injection. The EV71 VLPs elicited slightly higher neutralization titers against EV71 Bj08 compared to the heat-inactivated EV71. The denatured VLPs elicited lower neutralization titers than the purified VLPs, although they induced similar levels of IgG antibodies. These data are consistent with the previous report [3]. In vitro inhibition of EV71-mediated cytopathic effect (CPE) by anti-sera was illustrated by microscopic photographs. Serum samples were diluted 256-fold for neutralization assay. Virus-mediated CPE was remarkably found in cells infected by either EV71 Bj08 or BrCr-TR (Fig. 5a, b) after 6 days of infection. In contrast, no obvious CPE was observed in the cells without viral infection (Fig. 5c, d). Virus-induced CPE could be significantly suppressed by the addition of anti-VLP sera (Fig. 5e, $\mathrm{f}$ ) and anti-inactivated EV71 sera (Fig. 5g, h). Lower suppression of CPE was observed by using anti-denatured VLP sera (Fig. 5i, j), suggesting that antibody recognizing conformational viral epitopes are essential for VLP-induced immune protection against EV71.

\section{In vivo protection against lethal viral challenge in neonatal mouse model}

The in vivo protective ability of anti-sera against lethal EV71 challenge was evaluated in a neonatal mouse model and EV71 BrCr-TR was used as a representative high-virulence strain. $10 \mathrm{LD}_{50}$ of $\mathrm{BrCr}-\mathrm{TR}$ virus was mixed with sera from mice immunized with EV71 


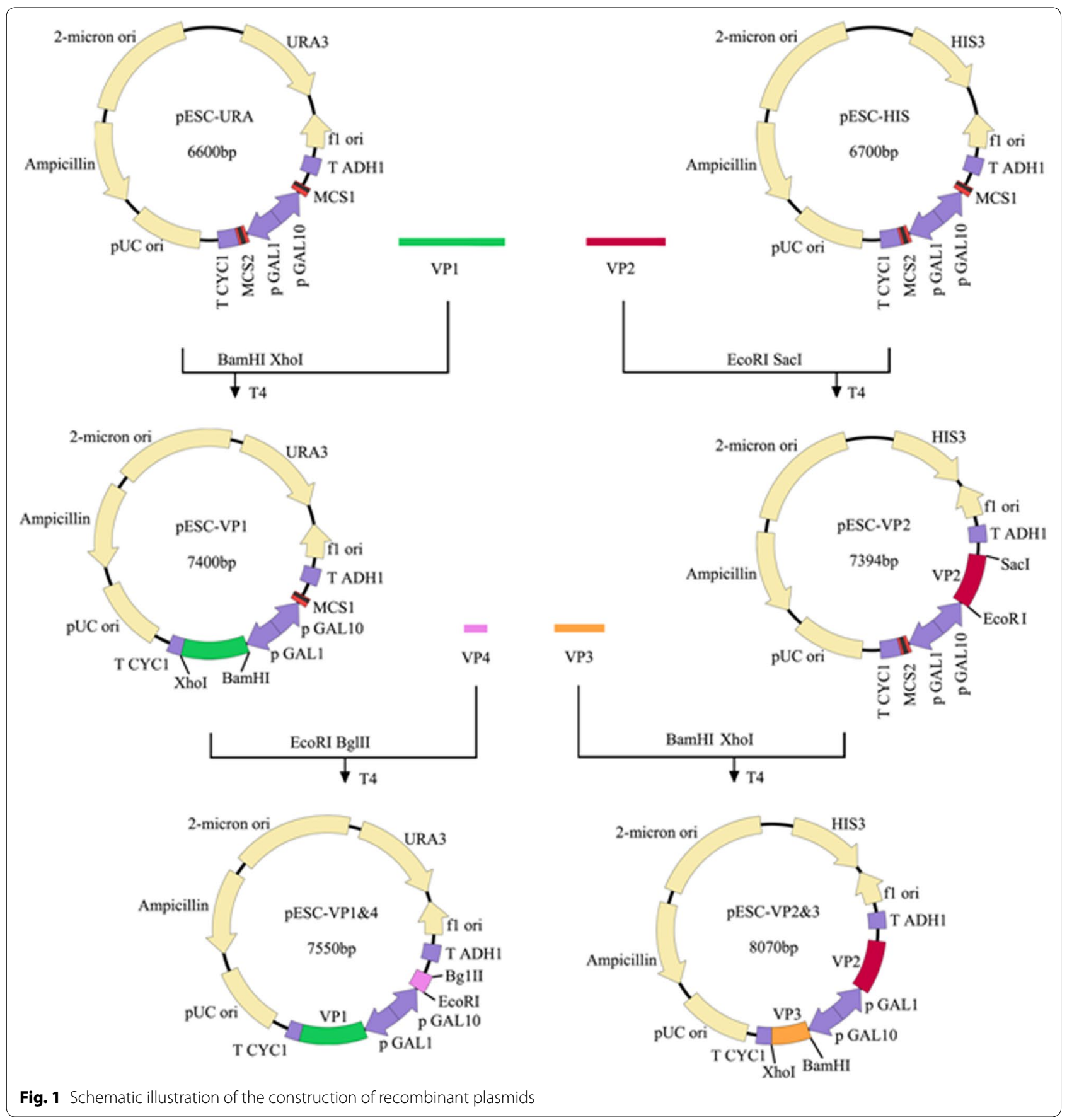

VLPs, inactivated-EV71 virus, yeast cell lysates and PBS. The mixture of EV71 virus and anti-sera was incubated overnight at $37{ }^{\circ} \mathrm{C}$ and used to inoculate intraperitoneally (i.p.) 1-day-old BALB/c suckling mice $(\mathrm{n}=10$ per group). Infection by BrCr-TR viral strain was used as positive control. The data showed that $90 \%$ of mice treated with EV71 virus mixed with the EV71 VLPs- and
inactivated-EV71 virus-immune sera remained healthy and survived until the end of the experiments. In contrast, mice inoculated with virus mixed with the yeast cell lysates and PBS-immune sera died at 16 days post-inoculation, indicating that EV71 VLPs and inactivated EV71 virus conferred immune protection against EV71 lethal challenge in vivo (Fig. 6). 
a

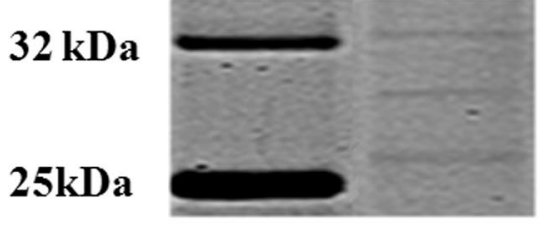

$32 \mathrm{kDa}$

b

$25 \mathrm{kDa}$

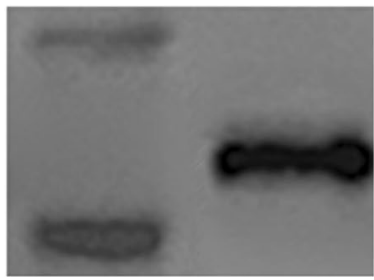

c

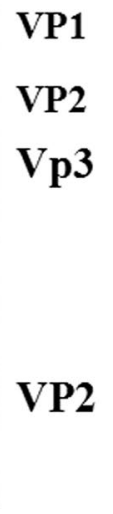

VLP

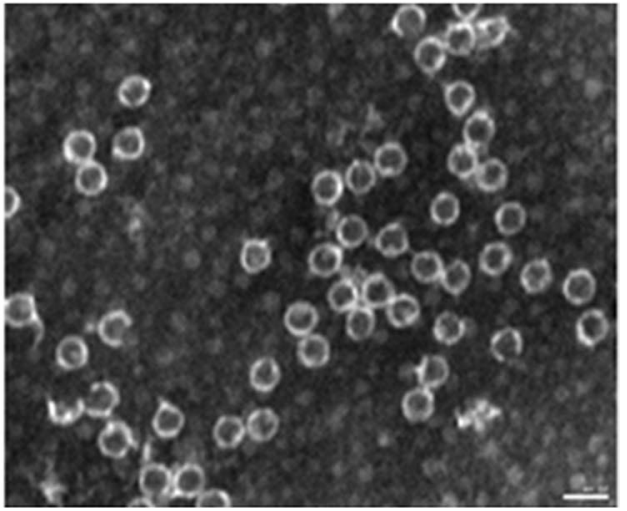

Fig. 2 Viral protein expression and electron microphotographs. a The expressions of EV71 structure proteins were visualized by SDS-PAGE. b The expression of EV71 VP2 was monitored using VP2-specific antibody MAB979 by Western blot. EV71 VLPS were isolated using sucrose and discontinuous cesium chloride ( $\mathrm{CsCl}$ ) gradient $(1.4,1.33,1.29$ and $1.25 \mathrm{~g} / \mathrm{ml})$ by ultracentrifugation. The formation of EV71 VLPS in yeast was monitored by electronic microscope. Size bar $50 \mathrm{~nm}$
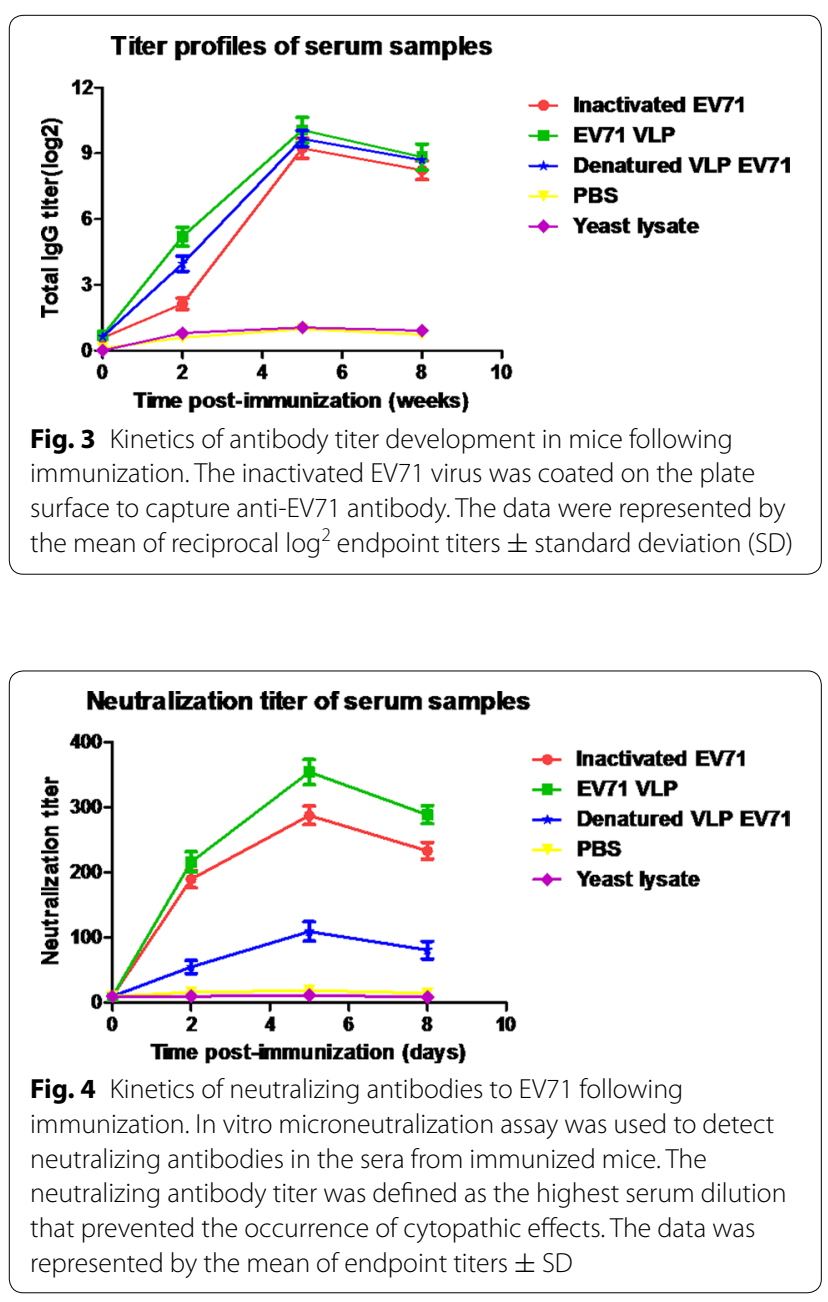

\section{Discussion}

Vaccination is a commonly used and cost-effective method for infectious disease control. Various types of vaccine candidates against EV71 have been evaluated in animal model, including recombinant subunits $[15,24]$, synthetic peptide vaccines [18-20], live attenuated vaccines $[25,26]$, VLP vaccines $[3,27,28]$, DNA vaccines [29] and formalin-inactivated virion vaccines [30-33]. Recombinant subunit vaccines can be produced from different expression systems. It has been found that EV71 capsid proteins VP1, VP2 and VP3 are immunogenic and capable of eliciting antibodies that recognize their corresponding viral proteins. Unlike VP2 and VP3, recombinant VP1 was capable of eliciting effective neutralizing antibody responses against EV71 [34]. Synthetic peptides containing neutralization epitopes are considered as good vaccine candidates providing well-defined immunogens and safety advantages. Two linear neutralizing epitopes SP70 and SP55 found in EV71 VP1, were capable of inducing neutralizing antibody responses in mice against EV71 virus by inhibiting viral infection at pre- or post-attachment steps [35]. Our previous study showed that immunization of $\mathrm{N}$ terminus of EV71 VP4 elicits cross-protective antibody responses [36]. Recently, a cross-neutralizing epitope was identified in EV71 VP2 [37]. However, neutralizing antibody responses induced by peptides are usually weak and require strong adjuvants. Live attenuated vaccines are widely used for viral disease prevention, however, the emergence of pathogenic viral revertants has raised vaccine safety concerns. Inactivated vaccine and VLP-based vaccine retain both 


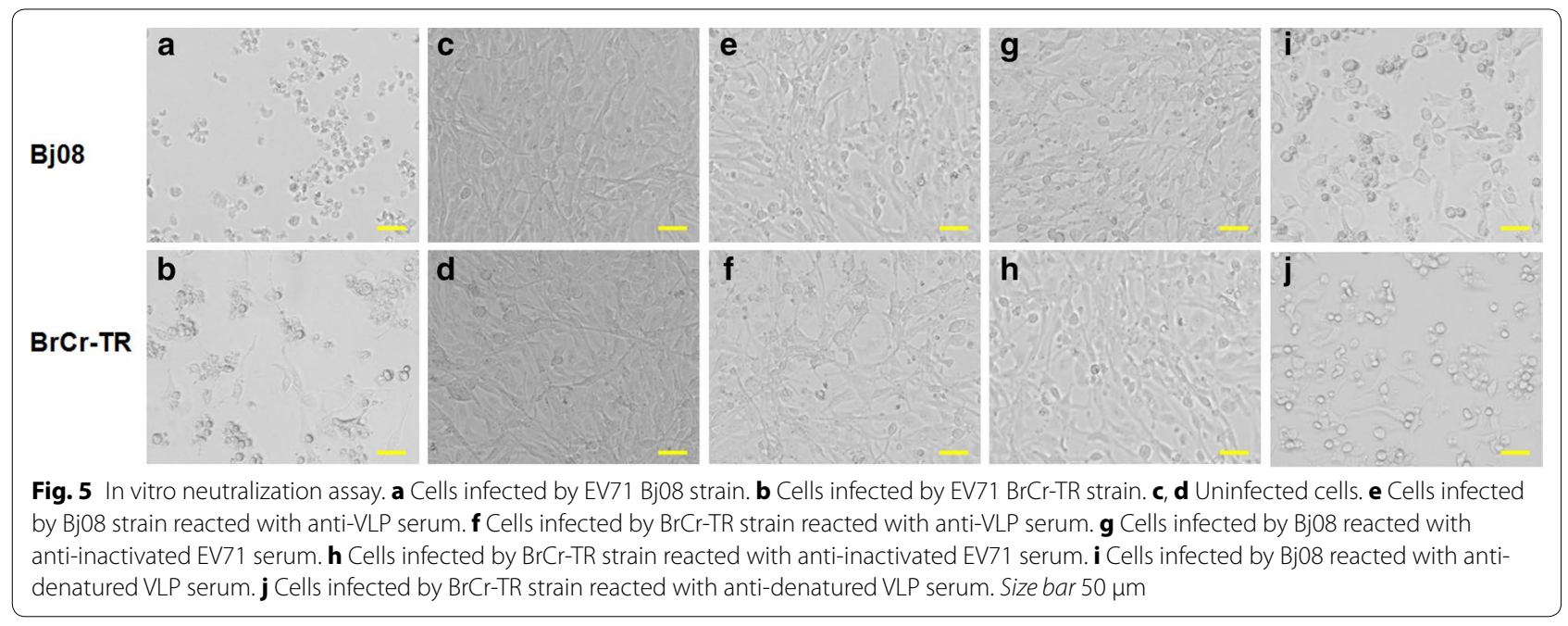

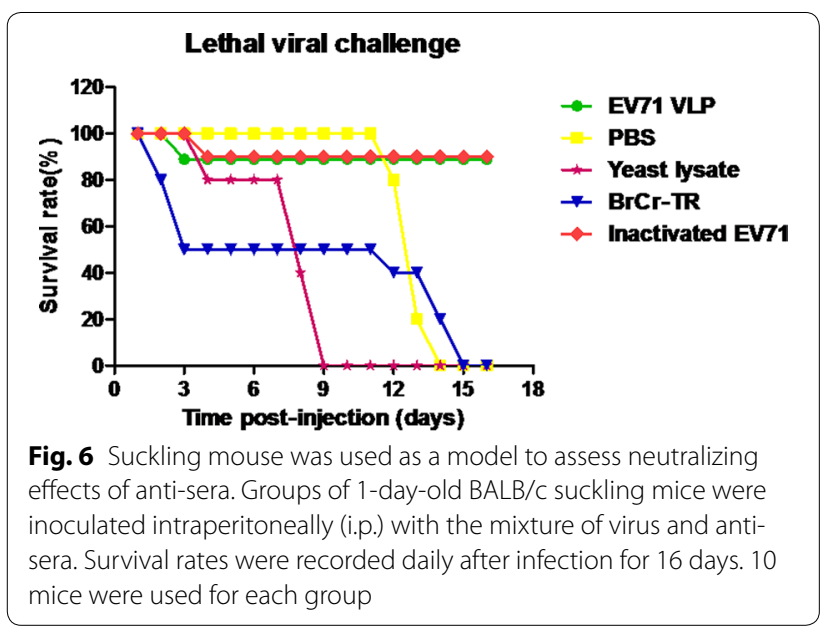

linear and conformational neutralizing epitopes responsible for eliciting potent neutralizing antibody responses against viral infection [38] and are thus widely accepted as effective vaccine candidates. VLP-based vaccine has a safety advantage over inactivated vaccine due to the lack of the viral genome.

Recombinant VLPs that mimic the conformation of authentic native viruses can be produced from variable expression systems such as insect cells, yeast and E. coli. EV71 VLPs have been successfully produced in variable expression systems via co-expression of $\mathrm{P} 1$ and $3 \mathrm{CD}$ viral proteins [28, 39]. 3CD is an EV71-encoded protease responsible for the digestion of $\mathrm{P} 1$ polyprotein into structural subunit proteins, which form EV71 capsids via self-assembly.

Two types of EV71 viral particles (E- and F-particles) have previously been produced from Vero cells cultured in a serum-free condition. SDS-PAGE and Western blot analysis illustrated that the E-particle was an immature particle containing incompletely cleaved VPO protein, while in F-particle, VP0 protein was fully cleavaged into VP2 and VP4 by autocatalytic processing. In addition, neutralization assay showed that the inactivated F-particle induced a more potent neutralizing antibody response against EV71 in the mouse model than the E-particle [40]. Thus, F-particle of EV71 is an ideal vaccine candidate to prevent EV71 infection. In the present study, we report a technique for production of EV71 F-particles in yeast cells. TEM analysis showed that EV71 VLPs were successfully generated in yeast cells through the co-expression of four EV71 capside proteins (VP1 to VP4) without using $3 C D$ protease. It has been reported that host cell apoptosis can be triggered by the coxsackievirus B3-encoded protease and HIV-encoded proteases induced cell death [41, 42]. Co-expression of P1 protein and 3CD can be used to produce EV71 VLP in different host cells. However, the effects of EV71-encoded protease on host cell apoptosis or death still remains to be elucidated.

EV71 is phylogenetically classified into three distinct genotypes: $\mathrm{A}, \mathrm{B}$, and $\mathrm{C}$ based on the genetic variation of VP1 sequences. Genotypes B and $C$ can be further divided into $\mathrm{B} 1-\mathrm{B} 5$ and $\mathrm{C} 1-\mathrm{C} 5$ subgenotypes, respectively [43, 44]. Recently, 3 new genotypes were reported, $D, E$ and $F$ subgenotypes [45, 46]. An ideal anti-EV71 vaccine should be able to provide broad protective activity against a wide spectrum of EV71 strains. One single serotype was reported in EV71 when measured by hyperimmune animal sera. However, antigenic variations have been identified recently in post-infection human sera when measured cross-neutralizing antibody titers against different EV71 genotype strains. Antigenic variation among different genogroups was reported [47]. Immunization of live attenuated EV71 vaccine (genotype 
A) induced the strongest neutralizing antibody responses against the homotype (genotype A) and weaker neutralizing antibody responses against other EV71 genotype strains such as B1, B4, C2 and C4, suggesting antigenic heterogeneity among EV71 isolates [26]. Five EV71 vaccine candidates are currently being evaluated in clinical trial. Genotype C4 and B4 viruses were selected for anti-EV71 vaccine development in mainland China and Taiwan, respectively. The inactivated EV71 C4 genotype vaccine could provide homogeneous and broad crossprotection against different subgenotypes of EV71 such as B4, B5, C2, C4 and C5 strains in health children and infants [48]. An potent cross-neutralizing antibody protection against EV71 subgenotypes B1, B4, B5 and C4A were also observed in B4-based vaccine treatment [49]. Based on the antigenic heterogeneity among EV71 isolates and the efficacy of multivalent VLP vaccine demonstrated by the successful application of bivalent and tetravalent HPV vaccine, multivalent VLP-based vaccine has a great potential in the development of a safe and cost-effective anti-EV71 vaccine with broad cross-protection.

\section{Conclusions}

The co-expression of four EV71 capsid proteins in yeast resulted in effective production of EV71 VLPs, which elicited potent anti-EV71 antibody responses and protected neonatal mice against lethal viral challenges. Multivalent EV71 VLP-based vaccine has a great potential to be a safe and cost-effective vaccine candidate with broad cross-neutralizing activities against EV71 infection.

\section{Methods}

\section{Construction of plasmids}

The coding sequence of EV71 P1 protein of C4 subgenotype was optimized according to the codon usage for S. cerevisiae. DNA fragment encoding P1 protein was then synthesized. VP1 gene was amplified using primers VP1-BamH1 (5'-AAGGATCCATGGGTGA CAGAGTCGCCGAT-3') and VP1-XhoI (5'-CCGCTC GAGTCATAAAGTAGTGATGGCT-3'. The PCR products were double-digested by $\mathrm{XhoI}$ and $\mathrm{BamH} 1$ and subsequently inserted into the vector pESC-URA (Invitrogen) to construct pESC-VP1. VP4 gene was amplified using primers VP4-EcoR1 (5'-CCGGAATTCATGG GATCACAAGTTTCA-3') and VP4-BglII (5'-GAAGA TCTCTTTAATGGGGCAGCCAT- $3^{\prime}$ ). The PCR fragments were further inserted into the vector plasmid pESC-VP1 at EcoR1 and BglII sites to yield pESC-VP1\&4. VP2 gene was amplified using primers VP2-EcoRI (5'-CGGAATTCATGTCTCCATCTGCCGAAGCA-3') and VP2-SacI (5'-AACGAGCTCCTGAGTAACGGC TTGCCT-3'). The amplified PCR products were then inserted into the vector pESC-HIS (Invitrogen) to construct pESC-VP2 after double-digestion by EcoR1 and $S a c$ I. VP3 gene was amplified using primers VP3-BamHI (5'-CGGGATCCATGGGTTTTCCTACAGAATTG-3') and VP3-XhoI (5'-CCGCTCGAGTTGTATTATTCCA GTCTG-3'). The amplified DNA fragments were then inserted into the plasmid pESC-VP2 at BamH1 and XhoI cutting sites to yield pESC-VP2\&3.

\section{Expression of recombinant protein in yeast}

The recombinant plasmids $\mathrm{pESC}-\mathrm{VP} 1 \& 4$ and $\mathrm{pESC}$ VP2\&3 were further co-transformed into yeast of INVSc1 strain (Invitrogen, USA) by using Sc EasyComp transformation kit (Invitrogen, USA) according to the instructions of the manufacturer. The yeast transformants were further selected onto a synthetic complete plates without uracil and histidine. Clonal isolates were then grown at $30{ }^{\circ} \mathrm{C}$ for $78 \mathrm{~h}$ in YPD containing $2 \%$ galactose to an optical density. After centrifugation, the harvesting cell pellets were broken with glass beads and cell lysates were analyzed for the expression of EV71 VP1.

\section{Purification of VLPs}

The yeast pellets were resuspended in sodium phosphate buffer ( $\mathrm{pH}$ 7.2) supplemented with $1 \times$ rotease inhibitor cocktail. Yeast cells were broken by using high-pressure homogenizer (APV-2000, Denmark) with a pressure of 1500 Bar. $25 \mathrm{U} / \mathrm{ml}$ of benzonase (Merck, USA) was further added into the cell lysates and incubated for $1 \mathrm{~h}$ at room temperature. Cellular debris was then removed by centrifugation at $12,000 \mathrm{~g}$ for $20 \mathrm{~min}$ at $4{ }^{\circ} \mathrm{C}$. $\mathrm{NaCl}$ was added into the supernatant at a final concentration of $500 \mathrm{mM}$ and polyethylene glycol 5000 (Sigma-Aldrich, USA) was added at a final concentration of $10 \%(\mathrm{w} / \mathrm{v})$. After an overnight mixture at $4{ }^{\circ} \mathrm{C}$, the supernatant was centrifuged at $12,000 \mathrm{~g}$ for $20 \mathrm{~min}$ at $4{ }^{\circ} \mathrm{C}$ and the pellets were resuspended into sodium phosphate buffer ( $\mathrm{pH} 7.2)$. Insoluble debris was removed by centrifugation at $10,000 \mathrm{~g}$ for $10 \mathrm{~min}$ at $4{ }^{\circ} \mathrm{C}$. The clarified supernatant was loaded onto the discontinuous sucrose gradient consisting of 15, 35 and $65 \%$ sucrose that was dissolved in PBS buffer. After ultracentrifugation at $100,000 \mathrm{~g}$ using SW32Ti rotor (Beckman, USA) for $6 \mathrm{~h}$, the white band between the interfaces of $15-35 \%$ sucrose was collected and loaded onto discontinuous cesium chloride $(\mathrm{CsCl})$ gradient $(1.4,1.33,1.29$ and $1.25 \mathrm{~g} / \mathrm{ml})$ and spun using SW32Ti rotor (Beckman, USA) for $21 \mathrm{~h}$ at 100,000g. The VLP-containing fractions were harvested, diluted with sodium phosphate buffer, and ultracentrifuged at $34,000 \mathrm{~g}$ for $6 \mathrm{~h}$ at $4{ }^{\circ} \mathrm{C}$ after dialyzed against low salt PBS buffer ( $\mathrm{pH}$ 7.4). The pelleted VLPs were resuspended in PBS and concentration was measured using Bradford protein assay kit (Bio-Rad, USA). 


\section{SDS-PAGE and western blotting}

The purified VLP samples were denatured by boiling for 10 min and loaded onto SDS-PAGE (12\%) gel for electrophoresis. The recombinant proteins were detected by Western blotting using a monoclonal antibody against VP2 (MAB979, Millipore, USA). Briefly, the proteins were transferred onto PVDF membrane, which were blocked with $2 \%(\mathrm{w} / \mathrm{v})$ BSA in TBS solution for $1 \mathrm{~h}$ at room temperature, and further washed three times with TBS containing $0.05 \%(\mathrm{v} / \mathrm{v})$ Tween 20. The membrane was then incubated with primary anti-VP1 and anti-VP2 antibodies, respectively, for $1 \mathrm{~h}$ at $37{ }^{\circ} \mathrm{C}$, and washed three times with TBS buffer. After incubation with the secondary goat anti-rabbit and goat anti-mouse antibodies conjugated with fluorescent dyes: IRDye $800 \mathrm{CW}$ (KPL, USA) for $45 \mathrm{~min}$, blotting images were acquired using the Odyssey infrared imaging system (Li-COR Biosciences, USA) and analyzed by the software provided by the manufacturer.

\section{Electron microscopy}

The formation of EV71VLPs was analyzed by electron microscopy as described previously [3]. Briefly, samples were adsorbed to carbon-coated copper grids and incubated for $1 \mathrm{~min}$. The grids were then negatively stained for $45 \mathrm{~s}$ with $2 \%$ phosphotungstic acid after washing twice with $\mathrm{PBS}$ and visualized using an electron microscope (H-7650, HITACHI, Japan).

\section{Immunization of animals}

Pathogen-free female BALB/c mice were purchased from Beijing HFK Bioscience Co. (Beijing, China). All animals were housed at pathogen-free conditions. Animal experiments were performed according to the current experimental protocols involving animal study approved by the Institutional Animal Care and Use Committee of Peking University. For mice experiments, five female BALB/c mice (6-8 weeks) per group were immunized with $20 \mu \mathrm{g} /$ mouse of one of the following samples: purified VLPs, denatured VLPs, beta-propiolactone-inactivated EV71 virus (Bj08 strain), yeast cell lysate or PBS. The immunization was boosted 3 weeks later with the same dosages. QuickAntibody $^{\mathrm{TM}}$ from KBQ Biotechnology Co. (Beijing, China) was used as an adjuvant. Control group was immunized with PBS plus adjuvant. The blood samples were collected at week $0,2,5,8$ and the sera were inactivated at $56{ }^{\circ} \mathrm{C}$ for $30 \mathrm{~min}$ and stored at $-80^{\circ} \mathrm{C}$.

\section{ELISA analysis}

Inactivated EV71 virus were used as the coating antigen to titrate anti-EV71 IgG levels in the serum samples by sandwich enzyme-linked immunosorbent assay (ELISA) as described previously [3]. Briefly, 96-well plates were coated with polyclonal anti-EV71 antibody overnight at $4{ }^{\circ} \mathrm{C}$ and blocked with the buffer containing $2 \%(\mathrm{w} / \mathrm{v})$ bovine serum albumin for $2 \mathrm{~h}$ at $37^{\circ} \mathrm{C}$. Inactivated EV71 virus was added to the well and incubated for $2 \mathrm{~h}$ after washing thrice with the buffer $(0.05 \%(\mathrm{v} / \mathrm{v})$ Tween 20 in PBS). The sera were analyzed at twofold serial dilutions by starting at $1: 100$. The plates were incubated at $37{ }^{\circ} \mathrm{C}$ for $1 \mathrm{~h}$ and washed thrice with buffer. HRP conjugated goat anti-mouse IgG (CWBIO, China) was then added into each well in a 1:2000 dilution, and incubated at $37{ }^{\circ} \mathrm{C}$ for $1 \mathrm{~h}$. The plates developed with TMB solution (Tiangen Biotech, China) in a dark room for 15 min after washing three times with buffer, and the reaction was stopped by adding $2 \mathrm{M} \mathrm{H}_{2} \mathrm{SO}_{4}$. The absorbance at $450 \mathrm{~nm}$ was evaluated using a microplatereader (Bio-Rad, USA).

\section{In vitro neutralization assay}

Neutralization assay was carried out as described previously [36]. Briefly, EV71 BJ08 (genotype C4) and BrCrTR (genotype A), were propagated in RD cells. The virus titers were determined in RD cells and expressed by the $50 \%$ tissue culture infective dose $\left(\mathrm{TCID}_{50}\right)$ according to the Reed-Muench method. To measure the neutralization titers, RD cells were cultured in the 96-well plates overnight until $60 \%$ confluence. Serum samples were twofold serially diluted using Minimum Essential Medium (MEM, Gibco ${ }^{\circledR}$ ) containing $2 \% \mathrm{FBS}$ and mixed with equal volume of EV71 (100 TCID 50 ). After incubation overnight at $37{ }^{\circ} \mathrm{C}$, the mixture was used to infect RD cells. The highest serum dilution, which could fully protect infected cells from developing cytopathic effects, was considered as neutralization titer.

\section{Mouse protection assay}

The protective efficacy of the immunized sera was evaluated by in vivo infection experiments. Briefly, $50 \mu \mathrm{l}$ of sera from mice immunized with recombinant VLPs, inactivated EV71, yeast cell lysate or PBS were incubated with $10 \mathrm{LD} 50$ of EV71 $\mathrm{BrCr}$-TR at $37{ }^{\circ} \mathrm{C}$ for $2 \mathrm{~h}$. Groups of 1-day-old BALB/c suckling mice ( $\mathrm{n}=10$ per group) were inoculated intraperitoneally (i.p.) with the mixture of virus and sera. All mice were monitored daily for the appearance of death for up to 16 days after inoculation.

\footnotetext{
Authors' contributions

The authors' contributions to this research work are reflected in the order shown. XWW contributed to the majority of experimental works and the writing of the manuscript. XQX and XS participated in EV71 virus preparation and their characterization. $M Z$ and $W L$ performed VLP expression and purification. LP performed ELISA analysis. SC participated in in vivo neutralization assay. WS and YMH directed the research, designed and coordinated the project, analyzed the data, and wrote the manuscript. BBY and YZ conceived the study and participated in its design. All authors read and approved the final manuscript.
} 


\section{Author details}

${ }^{1}$ College of Life Science and Bioengineering, Beijing University of Technology, 100 Pingleyuan, Chaoyang District, Beijing, People's Republic of China. 2 Department of Neurology, Beijing Ditan Hospital, Capital Medical University, Beijing, People's Republic of China. ${ }^{3}$ Research Center for Life Science, Beihua University, Jilin, People's Republic of China. ${ }^{4}$ Department of Virology, Institute of Medicinal Biotechnology, Chinese Academy of Medical Science, Beijing, People's Republic of China. ${ }^{5}$ Department of Laboratory Medicine and Pathobiology, University of Toronto, 2075 Bayview Avenue, Toronto M4N 3M5, Canada.

\section{Acknowledgements}

This work was supported by grants from International Science \& Technology Cooperation (No. 2011DFG33200), National High Technology Research and Development Program of China (863 Program, No. 2012AA02A400), Project supported by the National Natural Science Foundation of China (No. 31470076) and Jilin Program for Development of Science and Technology (No. 20106043, No. 2013(018).

\section{Competing interests}

The authors declare that they have no competing interests.

Received: 9 October 2014 Accepted: 30 November 2015 Published online: 25 January 2016

\section{References}

1. Schmidt NJ, Lennette $\mathrm{EH}, \mathrm{Ho} H \mathrm{H}$. An apparently new enterovirus isolated from patients with disease of the central nervous system. J Infect Dis. 1974;129(3):304-9.

2. Brown BA, Pallansch MA. Complete nucleotide sequence of enterovirus 71 is distinct from poliovirus. Virus Res. 1995;39(2-3):195-205.

3. Chung YC, Ho MS, Wu JC, Chen WJ, Huang JH, Chou ST, Hu YC. Immunization with virus-like particles of enterovirus 71 elicits potent immune responses and protects mice against lethal challenge. Vaccine. 2008;26(15):1855-62.

4. Tuthill T, Groppelli E, Hogle J, Rowlands D: Picornaviruses. In: Johnson JE, editor. Cell Entry by Non-Enveloped Viruses, vol. 343. Berlin Heidelberg: Springer; 2010. p. 43-89.

5. Chow M, Newman JFE, Filman D, Hogle JM, Rowlands DJ, Brown F. Myristylation of picornavirus capsid protein VP4 and its structural significance. Nature. 1987;327(6122):482-6.

6. Lewis JK, Bothner B, Smith TJ, Siuzdak G. Antiviral agent blocks breathing of the common cold virus. Proc Natl Acad Sci USA. 1998;95(12):6774-8.

7. Wang X, Peng W, Ren J, Hu Z, Xu J, Lou Z, Li X, Yin W, Shen X, Porta C, et al. A sensor-adaptor mechanism for enterovirus uncoating from structures of EV71. Nat Struct Mol Biol. 2012;19(4):424-9.

8. McMinn PC. An overview of the evolution of enterovirus 71 and its clinical and public health significance. FEMS Microbiol Rev. 2002;26(1):91-107.

9. Suzuki Y, Taya K, Nakashima K, Ohyama T, Kobayashi JM, Ohkusa Y, Okabe N. Risk factors for severe hand foot and mouth disease. Pediatr Int 2010;52(2):203-7.

10. Zeng M, El Khatib NF, Tu S, Ren P, Xu S, et al. Seroepidemiology of Enterovirus 71 infection prior to the 2011 season in children in Shanghai. J Clin Virol. 2012;53(4):285-9.

11. Wu Y, Yeo A, Phoon MC, Tan EL, Poh CL, Quak SH, Chow VTK. The largest outbreak of hand; foot and mouth disease in Singapore in 2008: the role of enterovirus 71 and coxsackievirus A strains. Int J Infect Dis. 2010;14(12):e1076-81.

12. Chen KT, Chang HL, Wang ST, Cheng YT, Yang JY. Epidemiologic features of hand-foot-mouth disease and herpangina caused by enterovirus 71 in Taiwan, 1998-2005. Pediatrics. 2007;120(2):e244-52.

13. Solomon T, Lewthwaite P, Perera D, Cardosa MJ, McMinn P, Ooi MH. Virology, epidemiology, pathogenesis, and control of enterovirus 71. Lancet Infect Dis. 2010;10(11):778-90.

14. Chen SC, Chang HL, Yan TR, Cheng YT, Chen KT. An eight-year study of epidemiologic features of enterovirus 71 infection in taiwan. Am J Trop Med Hyg. 2007;77(1):188-91.

15. Wu CN, Lin YC, Fann C, Liao NS, Shih SR, Ho MS. Protection against lethal enterovirus 71 infection in newborn mice by passive immunization with subunit VP1 vaccines and inactivated virus. Vaccine. 2001;20(5-6):895-904.

16. Liu CC, Chou AH, Lien SP, Lin HY, Liu SJ, Chang JY, Guo MS, Chow YH, Yang WS, Chang KHW, et al. Identification and characterization of a crossneutralization epitope of Enterovirus 71. Vaccine. 2011;29(26):4362-72.

17. Chang GH, Luo YJ, Wu XY, Si BY, Lin L, Zhu QY. Monoclonal antibody induced with inactived EV71-Hn2 virus protects mice against lethal EV71Hn2 virus infection. Virol J. 2010;7:106.

18. Foo DG, Alonso S, Phoon MC, Ramachandran NP, Chow VT, Poh CL. Identification of neutralizing linear epitopes from the VP1 capsid protein of Enterovirus 71 using synthetic peptides. Virus Res. 2007;125(1):61-8.

19. Foo DG, Alonso S, Chow VT, Poh CL. Passive protection against lethal enterovirus 71 infection in newborn mice by neutralizing antibodies elicited by a synthetic peptide. Microbes Infect. 2007;9(11):1299-306.

20. Liu JN, Wang W, Duo JY, Hao Y, Ma CM, Li WB, Lin SZ, Gao XZ, Liu XL, Xu YF, et al. Combined peptides of human enterovirus 71 protect against virus infection in mice. Vaccine. 2010;28(46):7444-51.

21. Kwag HL, Kim HJ, Chang DY. The production and immunogenicity of humanpapillomavirus type 58 virus-like particles produced in Saccharomyces cerevisiae. J Microbiol. 2012;50(5):813-20.

22. Villa LL, Costa RL, Petta CA, Andrade RP, Ault KA, Giuliano AR, et al. Prophylactic quadrivalent human papillomavirus (types $6,11,16$, and 18) L1 virus-like particle vaccine in young women: a randomised doubleblindplacebo-controlled multicentre phase II efficacy trial. Lancet Oncol. 2005;6(5):271-8.

23. Ludwig C, Wagner R. Virus-like particles-universal molecular toolboxes. Curr Opin Biotech. 2007;18(6):537-45.

24. Wang M, Jiang S, Wang Y. Recombinant VP1 protein expressed in Pichia pastoris induces protective immune responses against EV71 in mice. Biocheml Biophys Res Commun. 2013;430(1):387-93.

25. Chiu CH, Chu C, He CC, Lin TY. Protection of neonatal mice from lethal enterovirus 71 infection by maternal immunization with attenuated Salmonella enterica serovar Typhimurium expressing VP1 of enterovirus 71. Microbes Infect. 2006;8(7):1671-8.

26. Arita M, Nagata N, Iwata N, Ami Y, Suzaki Y, Mizuta K, Iwasaki T, Sata T, Wakita T, Shimizu H. An attenuated strain of enterovirus 71 belonging to genotype A showed a broad spectrum of antigenicity with attenuated neurovirulence in cynomolgus monkeys. J Virol. 2007;81(17):9386-95.

27. Chung CY, Chen CY, Lin SY, Chung YC, Chiu HY, Chi WK, Lin YL, Chiang BL, Chen WJ, Hu YC. Enterovirus 71 virus-like particle vaccine: improved production conditions for enhanced yield. Vaccine. 2010;28(43):6951-7.

28. Li HY, Han JF, Qin CF, Chen R. Virus-like particles for enterovirus 71 produced from Saccharomyces cerevisiae potently elicits protective immune responses in mice. Vaccine. 2013;31(32):3281-7.

29. Tung WS, Bakar SA, Sekawi Z, Rosli R. DNA vaccine constructs against enterovirus 71 elicit immune response in mice. Genet Vaccines Ther. 2007;5:6.

30. Dong C, Wang J, Liu L, Zhao H, Shi H, Zhang Y, Jiang L, Li Q. Optimized development of a candidate strain of inactivated EV71 vaccine and analysis of its immunogenicity in rhesus monkeys. Hum Vaccines. 2010;6(12):1028-37.

31. Liu L, Zhang Y, Wang J, Zhao H, Jiang L, Che Y, Shi H, Li R, Mo Z, Huang $T$, et al. Study of the integrated immune response induced by an inactivated EV71 vaccine. PLoS One. 2013;8(1):e54451.

32. Dong C, Liu L, Zhao H, Wang J, Liao Y, Zhang X, Na R, Liang Y, Wang L, Li Q. Immunoprotection elicited by an enterovirus type 71 experimental inactivated vaccine in mice and rhesus monkeys. Vaccine. 2011;29(37):6269-75.

33. Bek EJ, Hussain KM, Phuektes P, Kok CC, Gao Q, Cai F, Gao Z, McMinn PC. Formalin-inactivated vaccine provokes cross-protective immunity in a mouse model of human enterovirus 71 infection. Vaccine. 2011;29(29-30):4829-38.

34. Chou AH, Liu CC, Chang JY, Lien SP, Guo MS, Tasi HP, Hsiao KN, et al. Immunological evaluation and comparison of different EV71 vaccine candidates. Clin Dev Immunol. 2012;2012:831282.

35. Ye X, Ku Z, Liu Q, Wang X, Shi J, Zhang Y, Kong L, Cong Y, Huang Z. Chimeric virus-like particle vaccines displaying conserved enterovirus 71 epitopes elicit protective neutralizing antibodies in mice through divergent mechanisms. J Virol. 2014;88(1):72-81.

36. Zhao M, Bai Y, Liu W, Xiao X, Huang Y, Cen S, Chan PK, Sun X, et al. Immunization of $\mathrm{N}$ terminus of enterovirus 71 VP4 elicits cross-protective antibody responses. BMC Microbiol. 2013;10(13):196-287. 
37. Xu L, He D, Li Z, Zheng J, Yang L, Yu M, Yu H, Chen Y, Que Y, Shih JW, et al. Protection against lethal enterovirus 71 challenge in mice by a recombinant vaccine candidate containing a broadly cross-neutralizing epitope within the VP2 EF loop. Theranostics. 2014;4(5):498-513.

38. Pushko P, Pumpens P, Grens E. Development of virus-like particle technology from small highly symmetric to large complex virus-like particle structures. Intervirology. 2013;56(3):141-65.

39. Chung YC, Huang JH, Lai CW, Sheng HC, Shih SR, Ho MS, Hu YC. Expression, purification and characterization of enterovirus-71 virus-like particles. World J Gastroenterol. 2006;12(6):921-7.

40. Liu CC, Guo MS, Lin FH, Hsiao KN, Chang KH, Chou AH, Wang YC, et al. Purification and characterization of enterovirus 71 viral particles produced from Vero cells grown in a serum-free microcarrier bioreactor system. PLoS One. 2011;6(5):e20005.

41. Zaragoza C, Saura M, Padalko EY, Lopez-Rivera E, Lizarbe TR, Lamas S, Lowenstein CJ. Viral protease cleavage of inhibitor of kappaBalpha triggers host cell apoptosis. Proc Natl Acad Sci USA. 2006;103(50):19051-6.

42. Blanco R, Carrasco L, Ventoso I. Cell killing by HIV-1 protease. J Biol Chem 2003;278(2):1086-93.

43. Yoke-Fun C, AbuBakar S. Phylogenetic evidence for inter-typic recombination in the emergence of human enterovirus 71 subgenotypes. BMC Microbiol. 2006;6:74.
44. Zhang Y, Tan X, Cui A, Mao N, Xu S, Zhu Z, Zhou J, Shi J, Zhao Y, Wang $X$, et al. Complete genome analysis of the C4 subgenotype strains of enterovirus 71: predominant recombination C4 viruses persistently circulating in China for 14 years. PLoS One. 2013;8(2):e56341.

45. Rao CD, Yergolkar P, Shankarappa KS. Antigenic diversity of enteroviruses associated with nonpolio acute flaccid paralysis, India, 2007-2009. Emerg Infect Dis. 2012;18:1833-40.

46. Bessaud M, Razafindratsimandresy R, Nougairède A, Joffret ML, Deshpande JM, Dubot-Pérès A, et al. Molecular comparison and evolutionary analyses of VP1 nucleotide sequences of new African human enterovirus 71 isolates reveal a wide genetic diversity. PLoS One. 2014;9(3):e90624

47. Huang SW, Hsu YW, Smith DJ, Kiang D, Tsai HP, et al. Reemergence of enterovirus 71 in 2008 in Taiwan: dynamics of genetic and antigenic evolution from 1998 to 2008. J Clin Microbiol. 2009;47(11):3653-62.

48. Mao Q, Cheng T, Zhu F, Li J, Wang Y, Li Y, Gao F, Yang L, Yao X, Shao J, Xia $\mathrm{N}$, Liang Z, Wang J. The cross-neutralizing activity of enterovirus 71 subgenotype C4 vaccines in healthy chinese infants and children. PLoS One. 2013;8(11):e79599.

49. Chou AH, Liu CC, Chang JY, Jiang R, Hsieh YC, Tsao A, Wu CL, Huang JL. Formalin-inactivated EV71 vaccine candidate induced cross-neutralizing antibody against subgenotypes B1, B4, B5 and C4A in adult volunteers. PLoS One. 2013;8(11):e79783.

\section{Submit your next manuscript to BioMed Central and we will help you at every step:}

- We accept pre-submission inquiries

- Our selector tool helps you to find the most relevant journal

- We provide round the clock customer support

- Convenient online submission

- Thorough peer review

- Inclusion in PubMed and all major indexing services

- Maximum visibility for your research

Submit your manuscript at www.biomedcentral.com/submit
() Biomed Central 